This item was submitted to Loughborough's Research Repository by the author.

Items in Figshare are protected by copyright, with all rights reserved, unless otherwise indicated.

\title{
Reactivity: an issue for short-term pedometer studies?
}

PLEASE CITE THE PUBLISHED VERSION

http://dx.doi.org/10.1136/bjsm.2007.038521

\section{PUBLISHER}

BMJ (@ the authors)

VERSION

AM (Accepted Manuscript)

LICENCE

CC BY-NC-ND 4.0

\section{REPOSITORY RECORD}

Clemes, Stacy A., Natalie Matchett, and Sarah L. Wane. 2019. "Reactivity: An Issue for Short-term Pedometer Studies?". figshare. https://hdl.handle.net/2134/15579. 
This item was submitted to Loughborough's Institutional Repository (https://dspace.lboro.ac.uk/) by the author and is made available under the following Creative Commons Licence conditions.

\section{creative
commons}

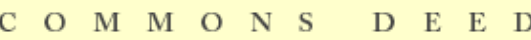

Attribution-NonCommercial-NoDerivs 2.5

You are free:

- to copy, distribute, display, and perform the work

Under the following conditions:

Attribution. You must attribute the work in the manner specified b the author or licensor.

Noncommercial. You may not use this work for commercial purposes.

No Derivative Works. You may not alter, transform, or build upon this work.

- For any reuse or distribution, you must make clear to others the license terms of this work.

- Any of these conditions can be waived if you get permission from the copyright holder.

Your fair use and other rights are in no way affected by the above.

This is a human-readable summary of the Leqal Code (the full license).

\section{Disclaimer 만}

For the full text of this licence, please go to: http://creativecommons.org/licenses/by-nc-nd/2.5/ 
Reactivity: an issue for short-term pedometer studies?

Stacy A Clemes, Natalie Matchett, Sarah L Wane

Keywords: habitual ambulatory activity, motivation, pedometer, validity, surveillance

Word count: 1400 (excluding title page, acknowledgements, competing interests statement, funding source, references, and 'what is already known' and 'what this study adds')

Address of all authors:

Department of Human Sciences

Loughborough University

Leicestershire

LE11 3TU 


\section{ABSTRACT}

Objectives: To investigate the influence of wearing a pedometer and recording daily step counts on ambulatory activity.

Methods: During the first visit to the laboratory, fifty healthy volunteers, blinded to the study aim, were provided with a sealed pedometer (New-Lifestyles NL-2000) and informed that it was a 'Body Posture Monitor' (sealed condition). Participants wore the pedometer throughout waking hours for one week. Upon returning to the laboratory step counts were downloaded and participants were informed that the device was actually a pedometer. They were requested to wear it unsealed for a second one week period, and to record their step counts in an activity log (unsealed condition).

Results: Mean daily step counts reported in the sealed condition (9541 \pm 3186 steps/day) were significantly lower than step counts reported in the unsealed condition (11385 \pm 3763 steps/day) $(\mathrm{p}<0.001)$.

Conclusions: Step counts increased significantly in the unsealed condition. Possible mechanisms for this include the knowledge of wearing a pedometer, the visible step count display and the completion of the activity log. This has validity implications for short-term studies (duration $\leq$ one week) investigating habitual pedometer-determined activity levels. 


\section{INTRODUCTION}

Pedometers are increasingly being used to objectively measure free-living ambulatory activity. In addition to their use as a surveillance tool, they are also a popular motivational device. The ability of the individual to receive immediate feedback on their accumulated step count is an important feature of the motivational aspect of the pedometer.[1, 2]

When used as a measurement tool, researchers often provide participants with unsealed pedometers (no restriction on participants viewing their step count) and request that they record their daily step count in an activity diary/step log. The impact of wearing a pedometer, and recording daily step counts, on participants' activity level (i.e. daily step count) has received little attention however. If activity changes as a result of wearing the pedometer, defined as reactivity,[3] this could affect the validity of pedometerdetermined activity data.

To date, only two studies have investigated whether reactivity exists in adult populations, when participants wear an unsealed pedometer and record daily step counts.[1, 4] Matevey et al.[1] and Eastep et al.[4] both reported minimal differences between unsealed and sealed (when the visible display of the pedometer is restricted) step counts. Similar findings have been reported when pedometer reactivity has been assessed in children.[5-7]

In the research outlined above [1, 5-7] participants have all been aware in the sealed condition that they were wearing a pedometer, or a device that measures physical activity,[4] which in itself may elicit some degree of reactivity. The aim of this study was to investigate the presence of reactivity by comparing step counts measured when participants were not aware that the device worn was a pedometer with step counts measured using an unsealed pedometer and participants recording their daily step count in an activity log. 


\section{METHODS}

\section{Participants}

A convenience sample of 50 adult participants (25 males, 25 females, mean age = $26.0 \pm 8.8$ years, mean $\mathrm{BMI}=23.0 \pm 4.0 \mathrm{~kg} / \mathrm{m}^{2}$ ), blinded to the study aim, volunteered to participate. The study received ethical approval from the Loughborough University Ethical Advisory Committee, and participants provided written informed consent. Participants were in good general health and none had any physical illnesses or disabilities that might affect their normal daily routine.

\section{Procedures and data analysis}

During the first visit to the laboratory, all participants were issued with a sealed New Lifestyles NL-2000 pedometer (New Lifestyles, Inc., Lees Summit, MO), shown to accurately detect steps taken in both laboratory [8-10] and free-living conditions [11]. Participants were informed that the device was a 'new body posture monitor that measures time spent in horizontal, seated and standing postures' (sealed condition). The tape used to seal the pedometer would tear if removed, therefore non-compliance would be obvious when participants returned to the laboratory. Participants were shown the correct position to wear the device, on the midline of the thigh, and were requested to wear it throughout waking hours for seven days, only removing when either bathing, showering or swimming.

During the second visit to the laboratory, daily step counts measured from the past seven days were recorded into an activity log by an experimenter using the NL-2000's memory function. Participants were informed that the device was actually a pedometer and they were requested to wear it throughout waking hours, unsealed, for another seven days and to record their daily step count in an activity log (unsealed condition).

During the two weeks of monitoring, all participants were encouraged not to make any changes to their typical daily routine. Upon completion of the study participants completed a questionnaire regarding their health and any changes to their normal routine, or general activity levels during the study period. 
Daily step counts recorded during the sealed and unsealed conditions were analysed using a repeated measures ANOVA to test for differences between the individual days of monitoring within each condition (i.e. sealed day 1 versus sealed day 2 etc.). Participants' mean daily step counts for the two conditions were calculated and compared using a paired sample t-test. The effect size of steps per day was calculated [12] to ascertain the size of the difference in step counts between conditions.

\section{RESULTS}

All participants reported no changes to their normal daily routine occurring throughout the two seven-day monitoring periods, and there was no evidence of any tampering with the pedometer seal.

A repeated measures ANOVA revealed that within each condition there were no differences in step counts between the individual days of monitoring. Mean daily step counts reported in the sealed condition (9541 \pm 3186 steps/day) were significantly lower than mean daily step counts reported in the unsealed condition (11385 \pm 3763 steps/day, $\mathrm{p}<0.001$, Figure 1), which resulted in an effect size of 0.65 .

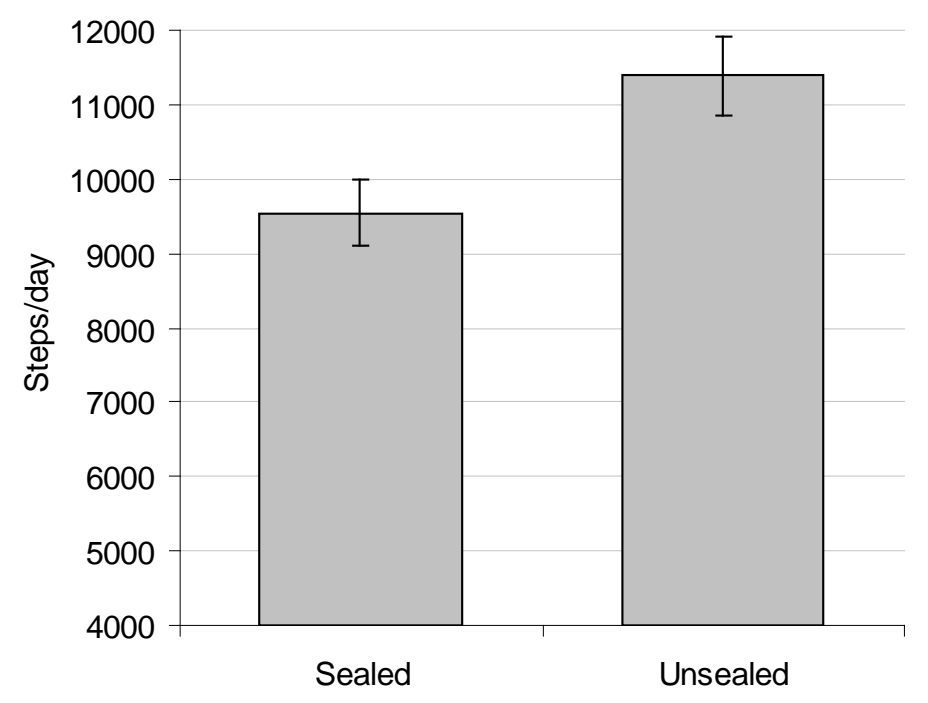

Figure 1. Mean daily step counts, with standard error bars, recorded in the sealed and unsealed conditions 


\section{DISCUSSION}

In this study population mean daily step counts increased significantly (1845 \pm 2191 steps/day) in the unsealed pedometer condition compared to the sealed condition. These findings differ to previous studies that have investigated reactivity to pedometers in adult populations.[1, 4] For example, Matevey et al.[1] reported no differences between sealed and unsealed pedometer step counts collected over two separate seven-day periods, from a sample of 28 participants. In this research however, participants were aware in the sealed condition that they were wearing a pedometer, which in itself may have elicited some degree of reactivity.

Eastep et al.[4] reported no differences between sealed and unsealed step counts collected from 21 participants enrolled in a 'Walking for Fitness' class. Eastep et al.[4] did observe however that walking behaviour decreased in a linear fashion throughout the two three-week conditions, suggesting that some degree of reactivity was present in both. Baseline step counts were not collected from participants before they enrolled in the walking class, it is therefore not known whether the step counts recorded were representative of typical adult behaviour. It was concluded from this research that a pedometer "feedback effect" may be present, but it may only last between one and two weeks.[4] Findings from the current study support this suggestion as no differences in step counts between the individual days of monitoring were observed in the unsealed condition, and the anticipated decrease in step counts occurring over the seven-day monitoring period was not observed, suggesting that reactivity may last for longer than one week.

There are a number of mechanisms that could account for the increase in daily step counts seen in the unsealed condition in the present study. These include: 1) the participants' knowledge that they were wearing a pedometer, and their daily step counts were being measured; 2) the feedback obtained from the visible display, it has been suggested that the pedometers ability to provide individuals with immediate feedback may serve as a behavioural modification tool;[2] and 3) the requirement for participants to complete a daily step log, which may have further heightened participant's awareness of their daily step count. In a minimal contact pedometer intervention study, Rooney et 
al.[2] observed that women who recorded their daily step count were more aware of their general activity levels and were more likely to set aggressive activity goals.

In conclusion, step counts increased significantly in the unsealed condition, this has validity implications for short-term studies (duration $\leq$ one week) investigating habitual pedometer-determined activity levels. Further research is required to 1) identify the mechanism responsible for this increase in activity, and 2) to determine the duration of this reactivity effect. 


\section{WHAT IS ALREADY KNOWN ON THIS TOPIC}

- Pedometers are increasingly being used as both a physical activity surveillance tool, and as a motivational device.

- The impact of wearing a pedometer, and recording daily step counts, on participants’ activity level has received little attention.

\section{WHAT THIS STUDY ADDS}

- This study compared step counts measured when participants were not aware that the device worn was a pedometer with step counts measured using an unsealed pedometer with participants recording their daily step count in an activity log.

- Step counts increased significantly in the unsealed condition, this has validity implications for short-term studies (duration $\leq$ one week) investigating habitual pedometer-determined activity levels.

\section{ACKNOWLEDGEMENTS}

Thanks must go to Dr Paula Griffiths and Sarah Hamilton for reading through and providing useful comments on the manuscript.

\section{COMPETING INTERESTS}

There are no competing interests associated with this research.

\section{FUNDING}

There was no funding source connected to this research, the study was conducted using existing equipment available in the Department of Human Sciences at Loughborough University. 


\section{REFERENCES}

1 Matevey C, Rogers L, Dawson E, et al. Lack of reactivity during pedometer selfmonitoring in adults. Measurement in physical education and exercise science 2006;10:1-11.

2 Rooney B, Smalley K, Larson J, et al. Is knowing enough? Increasing physical activity by wearing a pedometer. Wis Med J 2003;102:31-6.

3 Welk GJ, Corbin CB, Dale D. Measurement issues in the assessment of physical activity in children. Res Q Exerc Sport 2000;71:S59-73.

4 Eastep E, Beveridge S, Eisenman P, et al. Does augmented feedback from pedometers increase adults' walking behavior? Percept Mot Skills 2004;99:392-402.

5 Ozdoba R, Corbin C, Le Masurier G. Does reactivity exist in children when measuring activity levels with unsealed pedometers. Pediatr Exerc Sci 2004;16:158-66.

6 Rowe D, Mahar M, Raedeke T, et al. Measuring physical activity in children with pedometers: Reliability, reactivity, and replacement of missing data. Pediatr Exerc Sci 2004;16:343-54.

7 Vincent SD, Pangrazi RP. Does reactivity exist in children when measuring activity levels with pedometers? Pediatr Exerc Sci 2002;14:56-63.

8 Crouter SE, Schneider PL, Bassett DR, Jr. Spring-levered versus piezo-electric pedometer accuracy in overweight and obese adults. Med Sci Sports Exerc 2005;37:1673-9.

9 Crouter SE, Schneider PL, Karabulut M, et al. Validity of 10 electronic pedometers for measuring steps, distance, and energy cost. Med Sci Sports Exerc 2003;35:1455-60.

10 Schneider PL, Crouter SE, Lukajic O, et al. Accuracy and reliability of 10 pedometers for measuring steps over a 400-m walk. Med Sci Sports Exerc 2003;35:1779-84.

11 Schneider PL, Crouter SE, Bassett DR. Pedometer measures of free-living physical activity: comparison of 13 models. Med Sci Sports Exerc 2004;36:331-5.

12 Field A. Discovering statistics using SPSS. London: Sage 2005: 32-33.. 